indifference to expanding natural resources, provided profits are quick and large, in the closing chapters of his book, which ably deals with the biology of whales and their exploitation by man. Part I describes the different species of the larger whales and gives much information on many aspects of their lives; Part II is a succinct history of whaling-an excellent account compressed into the compass of 150 pages. It will give the interested general reader a reliable summary of the life and death of some of these most interesting mammals which, though often glimpsed at sea, are tantalisingly remote from close observation. There is an index, a short list of books for further reading, a useful collection of text figures and some interesting photographs.

L. H. MATTHEWS

\title{
The Last Resource: Man's Exploitation of the Oceans, by Tony Loftas. Pelican, 50p.
}

It is apposite that this book, first published in 1969, and now revised and issued as a paperback, should appear now with the UN Conference on the Law of the Sea scheduled to begin in Santiago in February 1974. It gives a good review of the present state of exploitation of the ocean for food, minerals, pharmaceuticals, water, energy, transport and military purposes; the concluding section deals with the debate about ocean resources which has resulted in that conference being held. Tony Loftas packs a considerable amount of information into his chapters but still manages to be readable and interesting. The book is well-balanced, and when he examines possible future developments he is careful to avoid the pitfall of moving into the realms of science fiction.

It is a pity, however, that he has not brought it up-to-date in a number of important respects. For example, he rightly points to the fact that there is too much fishing effort in the North Atlantic, but he does not mention the recent agreement between the 15 member countries of the International Commission for the Northwest Atlantic Fisheries fixing catch quotas for different species of fish in a number of areas, which is a significant step forward in the management of fish-resources. Similarly, he gives the impression that the beam trawl is outmoded, whereas recent developments in the Netherlands have made it an extremely efficient device that is posing serious problems for the conservation of sole and plaice, and, although he gives a good account of the British attempts to develop marine fish and shellfish cultivation systems, he does not include the latest economic assessments which show that it is unlikely to be economic to 'farm' a common fish like plaice but that the 'farming' of species like turbot may eventually be possible.

The marine pollution section describes the recent conventions to prevent pollution by dumping from ships, but makes no mention of the other recommendations of the UN Stockholm Conference on the Human Environment, nor does it mention that the so-called high levels of mercury in tuna fish are now found to have been present for decades and not to be an effect of pollution.

There are, too, errors in some explanations of scientific findings: for example, a faulty account of the reasoning which allows the maximum sustainable yield of a fish stock to be determined, and the explanation of the development of the seasonal thermocline leads the reader to believe that sea water has its maximum density at a temperature of $4^{\circ} \mathrm{C}$ - this is the case for fresh water but sea water has a maximum density at about minus $2^{\circ} \mathrm{C}$. Finally, there is at times a tendency to turn hypotheses into hard fact, as in the statement that PCBs were the cause of the seabird wreck in the Irish Sea 
in 1969 , whereas the scientific report issued by the Natural Environment Research Council goes no further than saying that no one factor, natural or artificial, can be regarded with certainty as the main cause of the incident.

A. J. LEE

\section{Sea Turtles: Their Natural History and Conservation, by Robert Bustard. Collins, $£ 3$. Kay's Turtles, by Robert Bustard. Collins, $£ 1.95$.}

Dr. Bustard is well known for his work on the ecology and conservation of Australian reptiles. He is one of the several dedicated men who have contributed so much to our knowledge of sea turtles during recent years, and who are making great efforts to ensure the survival of these attractive and fascinating creatures. This book embodies the results of nearly ten years' research, mainly on the shores of Queensland. It reviews the natural history of the seven living species in considerable detail, including an excellent account of the flatback turtle Chelonia depressa, which shows convincingly that this form, found only in Australian waters, is specifically distinct from the green turtle $C$. mydas. There is, too, an interesting account of the author's own research programme, involving the tagging and recapture of many adults, together with extensive studies on nesting, egg development and emergence of the hatchlings.

A substantial part of the book deals with conservation. For several hundreds of years turtles have been ruthlessly persecuted by man, and as Bustard remarks, all early nautical and colonial activity in the New World tropics was in some way dependent on these luckless animals. Accounts of turtle exploitation make harrowing reading since much needless cruelty has been involved. Large populations have been virtually exterminated in recent years, especially in the Caribbean. It is particularly sad that the huge leathery turtle, so distinct from other living species, should be critically endangered.

The government of Queensland has already introduced enlightened measures of protective legislation and it may be hoped that the turtle population will be able to flourish there with the minimum of disturbance. However, turtles, especially the green turtle, represent a great potential asset to mankind, since both eggs and adults are suitable food. Bustard advocates properly controlled farming as the best method of rational exploitation. The farms must, of course, be self-supporting, breeding from their own stock and not depleting the nests of local wild populations. The rearing of a quota of young turtles through the vulnerable period of early infancy and their subsequent release into the wild would be an essential part of such projects.

This is a stimulating book on an important subject. It is well illustrated by original photos, with an identification key and a bibliography.

It must be very difficult to write a good book about a 'personal' relationship between a human being and another kind of animal-especially when that animal is a turtle. Dr. Bustard has told very well his story about a friendly association between Kay, a Melanesian girl from the Torres Strait, and two or three green turtles which come to mate and nest on the Great Barrier Reef, described in his article in Oryx, May 1973. The association begins when Kay helps one of these turtles called Ruth, handicapped by an injured flipper, to dig her nest. Turtles are very shy, and Kay must have some special affinity with these creatures since she is able to lie alongside them on the beach and swim with them in a way which few if any other observers have succeeded in doing. The author describes their association in an objective and unsentimental fashion and takes us through 